DOI 10.37882/2223-2982.2021.02.06

\title{
ИСТОРИЯ И ТЕНДЕНЦИЯ РАЗВИТИЯ ТИФЛОКОММЕНТИРОВАНИЯ В КИТАЙСКОМ ЯЗЫКЕ
}

\section{HISTORY AND DEVELOPMENT TREND OF AUDIO DESCRIPTION IN CHINESE \\ Wang Zou Ying}

Summary: This article discusses the problem of the development of audio description in China: in particular, it is noted that the active development of audio description throughout the world, incl. and China, as well as the formation of this direction of linguistic translation (as a separate institution) began only at the end of the twentieth century. At the same time, it is indicated that the provision of audio description practically does not exist on the television channels of China; this type of translation of visual information for the visually impaired and in cinemas, museums and theaters is poorly developed. This issue is actively being worked out by various non-governmental organizations engaged in social activities in the country: The Hong Kong Society for the Blind, The Disabled Association Hong Kong, etc. On the basis of the analysis carried out, the author argues that, compared with Western countries, audio description in China is a relatively young direction of translation studies, which requires more detailed study.

Keywords: audio description, audiovisual translation, translation methodology, Chinese, direction of linguistic translations.
$\mathrm{B}$ научных исследованиях подавляющего большинства зарубежных ученых понятие «тифлокомментирование» зачастую определяется как «аудиоописание/аудиодескрипция». Возникновение единства терминологии можно отнести к первичности появления термина «Audio Description» в США с последующим влиянием работ американских ученых на развитие ти $\phi-$ локомментирования во многих странах мира [8, с. 33]. Однако, по мнению целого ряда отечественных ученых, термин «тифлокомментирование» является более широким по смыслу, чем термин «аудиодескрипция», так как подразумевает использование не только звуковых методов, но и письменных, печатных [1, с. 494; 9, с. 217; 10]. Например, описание для слепых картины, фотографии, географической карты или чертежа может быть выполнено не только в звуковом формате, но и на бумаге.

Подобной точки зрения придерживаются и такие отечественные ученые, как Н.К. Гарбовский и О.И. Костикова, в чьих работах отмечается, что тифлокомментирование имеет достаточно длительную историю становления и развития [4, с. 17-18]: оно возникло сразу после формирования человеческой речи и одновременно с появлением первого слепого человека.

\author{
Ван Цзоу Ин \\ Аспирант, МГУ им. М.В. Ломоносова \\ woaiyehehua@gmail.com
}

Аннотация: В данной статье рассматривается проблема развития тифлокомментирования в Китае: в частности, отмечается, что активное развитие тифлокомментирования во всем мире, В т.ч. и Китае, а также формирование данного направления лингвистических переводов (как отдельного института) началось только с конца XX века. При этом указывается, что обеспечение тифлокомментированием практически не существует на телевизионных каналах Китая; слабо развит данный вид перевода визуальной информации для слабовидящих и в кинотеатрах, музеях и театрах. Активно данный вопрос прорабатывается различными неправительственными организациями, занимающимися социальной деятельностью в стране: The Hong Kong Society for the Blind, The Disabled Association Hong Kong и пр. На основе проведенного анализа автором утверждается, что по сравнению с западными странами тифлокомментирование в Китае - относительно молодое направление переводоведения, требующее более детальной проработки.

Ключевые слова: тифлокомментирование, аудиовизуальный перевод, методология перевода, аудиодескрипция, китайский язык, направление лингвистических переводов.

Тифлокомментирование как методология перевода информации для слабовидящих была сформулирована в 1975 году американцем Грегори Фрейзером и начала распространяться в США и Европе с конца 80-х и начала 90-х годов [2, с. 50]. Активное развитие тифлокомментирования во всем мире, в т.ч. и Китае, а также формирование данного направления лингвистических переводов (как отдельного института) началось только с конца XX века. Таким образом, тифлокомментирование существует в западном мире уже более 25 лет, в Европе практика применения тифлокомментирования регулируется на законодательном уровне [3, с. 21-22; 5, с. 2127]. Что касается Китая, то развитие тифлокомментирования в данной стране все еще находится на ранней стадии, однако, это не связано с отсутствием спроса на данный вид перевода или отсутствием проблем адаптации слабовидящих людей в социуме. По данным Всемирной организации здравоохранения, при общей численности населения более 1,3 млрд. человек, в Китае насчитывается около 75 млн. человек с теми или иными нарушениями зрения, из которых 8 млн. человек являются слепыми и 67 млн. человек имеют слабое зрение [12, с. 58-59].

Наука о переводах в китайском языке имеет свою 
специфику [6, с. 5]: не исключением является и тифлокомментирование как часть науки о переводах. Так, обеспечение тифлокомментированием практически не существует на телевизионных каналах Китая. Слабо развит данный вид перевода визуальной информации для слабовидящих и в кинотеатрах, музеях и театрах. Кроме того, не существует никаких законодательных требований в отношении предоставления автономии в средствах массовой информации [7, с. 4]. При этом развитие тифлокомментирования в китайском языке ограниченно территориально: сравнительно активно развитием данного направления переводов занимаются исключительно крупные города, такие как Пекин, Шанхай и Гонконг.

Поскольку исследуемый вид перевода не регулируются законом, предоставление тифлокомментирования в Китае на институциональном уровне очень ограничено. Информированность об особых потребностях людей со слабым зрением в отношении их доступа к средствам массовой информации начала повышаться в Китае только с 2009 года. К сожалению, данный вопрос обеспокоил и продолжает беспокоить до сих пор, не государственные власти Китая, а неправительственные организации (далее НПО), занимающиеся социальной деятельностью в стране.

В настоящее время наиболее видными организациями по развитию тифлокомментирования на китайском языке являются: The Hong Kong Society for the Blind (далее - HKSB) (Гонконгское общество для слепых) и The Disabled Association Hong Kong (далее - DAHK) (Ассоциация инвалидов Гонконга). НKSB в основном предоставляет тифлокомментирование фильмов, разрабатывает тифлокомментарии для экскурсий, а иногда для спектаклей, выставок и исполнительских искусств. DАНK в основном разрабатывает тифлокомментарии для спектаклей, исполнительских искусств и выставок [11, с. 233]. В июле 2012 года в рамках HKSB была создана учебная группа по тифлокомментированию, и сегодня на ежемесячной основе проводятся групповые встречи, для обмена опытом, идеями по улучшению системы тифлокомментирования, прохождения тренингов и улучшения своих навыков. Кроме того, члены группы могут предложить мероприятия по дальнейшему обучению и деятельности в области тифлокомментирования.

С марта 2009 года HKSB предлагает регулярный показ фильмов, который проводится два-три раза в месяц в штаб-квартире организации. Из-за проблем, связанных с авторским правом, может быть обеспечен только прямой эфир - вместо предварительно записанного тифлокомментирования. До настоящего времени было организовано более 120 кинопоказов с прямыми трансляциями фильмов, в основном на кантонском диалекте, а также на диалекте путунхуа [11, с. 235]. В рамках данных кинопоказов было озвучено посредством тифлокоммен- тирования около 90 различных фильмов.

C 2010 года был выпущен ряд фильмов с тифлокомментированием на DVD. B сентябре 2010 года в Китае был выпущен первый DVD с тифлокомментированием на кантонском диалекте на фильм 唐山大地震 [After Shock] (Feng Xiaogang 2010). Сегодня среди наиболее известных кинолент на китайском языке, содержащих тифлокомментирование можно выделить такие, как:

一 單身男女 [Don't Go Go Breaking My Heart] (Johnnie To and Ka-Fai Wai);

— 奪命金 [Life Without Principle] (Johnnie To);

— 桃姐 [A Simple Life] (Ann Hui);

— DIVA華麗之後 [DIVA] (Heiward Mak);

一 大上海 [The Last Tycoon] (Jing Wong);

— 葉問:終極一戰 [Ip Man:The Final Fight] (Herman Yau);

— 盲探 [Blind Detective] (Johnnie To).

В развитии тифлокомментирования на китайском языке следует также отметить деятельность общественной теле-радио вещательной компании Radio Television Hong Kong (далее - RTHK). В марте 2013 года компания запустило программу «Аудио-кино» [光影無限LIKE - 電 影/舞台劇], в рамках которой транслируются фильмы на кантонском диалекте с тифлокомментариями в последнее воскресенье каждого месяца. Иногда в рамках программы проигрываются кантонские фильмы, которые доступны на DVD.

В конце 2000-х годов DAHK открыла импровизационный театр «Playback for ALL», спектакли которого содержат тифлокомментарии. Обычно театр ставит от трех до четырех пьес в год. Во время двухчасового спектакля ведущий приглашает некоторых зрителей рассказать свою собственную историю, связанную с темой спектакля. Затем исполнители импровизируют и разыгрывают рассказанные истории на сцене. DAHK также предоставляет тифлокомментирование и для других видов исполнительского и изобразительного искусства, таких, как гонконгский балет «Лебединое озеро», мюзикл «Животноводческая ферма» и выставка картин в Гонконге «Лучшие семейные традиции».

С начала 2011 года HKSB организует экскурсии, сопровождаемые тифлокомментированием: сегодня доступны такие экскурсионные программы, как посещение здания Законодательного совета, трамвайные экскурсии и экскурсия по Гонконгскому Ветландскому парку. Наибольший интерес для развития тифлокомментирования представляют трамвайные экскурсии HKSB. В ходе проведения экскурсий всем участникам выдается гарнитура; все участники прослушивают аудио дескриптора, который рассказывает о местах и зданиях, которые проезжает экскурсионная группа, после чего эксперт рассказывает о самом трамвае и его истории, чтобы обогатить культурные знания участников. Посетители также имеют 
возможность принять участие в сенсорной экскурсии. Участникам предоставляются небольшие модели трамваев и образцы билетов, которые можно исследовать тактильно. Посетители могут прикоснуться к различным частям экскурсионного трамвая (деревянным сиденьям, потолку) и почувствовать текстуры и формы.

В 2013 году HKSB организовала для своих членов три визита в Гонконгский Ветландский парк. В ходе проведенных экскурсий тифлокомментирование, как и в предыдущем случае включало 2 уровня: аудиодискрипцию, посредством ушной гарнитуры, и сенсорное исследование парковых объектов. Тифлокомментирование в Гонконге применяется и в рамках спортивных мероприятий. Так, организация Blind Sports Hong Kong (далее - BSHK, 香 港失明人健體會) предлагает регулярные тренировки по бегу, обеспеченные тифлокомментированием [11, с. 237]. В этом случае направляющий бегун описывает элементы движений на растяжку во время тренировки. Во время бега дискриптор описывает состояние дороги и любые препятствия, иногда делает описание пейзажей, зданий и предметов, которые группа бегунов встречает по пути следования.

В контексте развития тифлокомментирования в китайском языке следует также выделить деятельность публичной Китайской библиотеки Брайля (www.blc.org.cn), основанной в Пекине в 2011 году, которая предоставляет услуги тифлокомментирования для удовлетворения особых потребностей людей с той или иной степенью нарушения зрения. В структуре данной библиотеки присутствует Центр аудиодескрипции, сотрудники которого отвечают за создание тифлокомментариев. Фильмы с тифлокомментариями в библиотеке показываются еженедельно. Кроме того, для повышения уровня доступности тифлокомментирования на китайском языке для широкого круга пользователей, записи с тифлокомментариями библиотека загружает на свой официальный веб-сайт.

Значительный вклад в развитие тифлокомментирования вносит Пекинский центр образования и культурного обмена Хонгдан (www. hongdandan.org), предлагающий услуги тифлокомментирования на регулярной основе с 2005 года. Фильмы, содержащие тифлокомментарии, создаваемые данной организацией, выходят в прямой эфир каждую неделю по нескольким радиоканалам. В 2009 и 2010 годах, соответственно, центр расширил территориальную сферу своей деятельности, включив в них Тяньцзинь и Чэнду.

В Шанхае в 2009 году была открыта доступная Китайская федерация инвалидов «Катэй», обслуживающая слабовидящих людей. С 2012 года в кинотеатре «Катэй» на ежемесячной основе транслируются фильмы содержащие тифлокомментарии. При поддержке и финансировании организации Create Hong Kong с марта 2018 года по апрель 2019 года в Китае осуществлялась целевая гонконгская программа развития аудиодескрипции под названием «Гонконгская аудиодескрипция в схеме развития кинематографии» [8, с. 36]. В рамках этой программы стажеры, участвующие в тифлокомментировании на китайском языке в различных сферах деятельности, приняли участие в семинарах, практикумах и конференции. В конце июля и начале августа 2019 года был проведен масштабный пятидневный профессиональный семинар в Гонконге специалистами из США и Тайваня. Эксперты научили участников, как писать сценарии тифлокомментирования, описывать фильмы и изображения (фотографии). Семинар посетили около 100 участников, около 60 из которых получили сертификаты в двух категориях: «Базовая теория» и «Практика».

За последние 20 лет в высших учебных заведениях Гонконга было введено несколько факультативных курсов по тифлокомментированию: Йеунг разработал набор 30-часовых учебно-методических материалов по тифлокомментированию в рамках курса письменного и устного перевода в Гонконгском баптистском университете. Материал включает упражнения по исследуемой тематике для драмы, танца, ксиква (китайская опера), фильмов, картин, экскурсий по музеям и общественных мероприятий. Поскольку в Китае до XXI века не существовало отдельного курса тифлокомментирования для обучения студентов письменному и устному переводу, в 2006 году Гонконгский баптистский университет включил курс тифлокомментирования в класс «Перевод через средства массовой информации», модуль по межсемиотическому переводу, также охватывающий устный и адаптационный перевод.

С 2011 года в колледже высшего образования Чу Хай действуют 3 факультативных курса по тифлокомментированию: «Конвергентный перевод», «Аудиовизуальный перевод» и «Медиа-коммуникация для исполнительских видов искусства и развлечений». В то время как первые два курса сосредоточены только на тифлокомментировании для фильмов, последний курс посвящен тифлокомментированию для исполнительских видов искусств, а также для развлекательных мероприятий.

Таким образом, по сравнению с многочисленными западными странами тифлокомментирование в Китае относительно молодое направление переводоведения. Однако, как показало проведенное исследование, за последние несколько лет наблюдается быстрый рост в развитии данного направления аудиовизуального перевода. Кроме того, следует отметить, что в материковом Китае тифлокомментирование реализуется в весьма ограниченном варианте, а именно задействовано в основном в киноиндустрии. При этом наиболее развитым регионом в исследуемой сфере на сегодняшний день является Гонконг. 
ЛИТЕРАТУРА

1. Александрова Е.В. Перевод аудиодескрипции как альтернатива создания нового описания / Е.В. Александрова // Мир науки, культуры, образования. 2019. - № 2(75). - C. 493-495.

2. Борщевский И.С. Аудиодескрипция (тифлокомментирование) как вид перевода / И.С. Борщевский // Филология и лингвистика. - 2018. - № 3(9). - С. 48-52.

3. Ваньшин С.Н. Тифлокомментирование, или словесное описание для слепых: инструкт.-метод. пособие / С.Н. Ваньшин; под ред. В.С. Степанова, С.Н. Ваньшина. - М.: ИПТК «Логосвос», 2011. - 62 с.

4. Гарбовский Н.К. Перевод и общество / Н.К. Гарбовский, О.И. Костикова // Вестник Московского университета. Серия 22. Теория перевода. - 2018. - № 1. C. $17-40$.

5. Гробер Е.М. Тифлокомментирование как териоморфное проявление социокультурного феномена XXI века / Е.М. Гробер // Концепт. - 2014. - № 20. C. 2126-2130.

6. Костикова 0.И. Междисциплинарная интеграция как вектор развития науки о переводе / 0.И. Костикова // Вестник Московского университета. Серия 22. Теория перевода. - 2016. - № 4. - С. 5-6.

7. Костикова 0.И. Наука о переводе в Китае / 0.И. Костикова // Вестник Московского университета. Серия 22. Теория перевода. - 2017. - № 3. - С. 3-5.

8. Обиух П.А. Пособие по тифлокомментированию / П.А. Обиух, М.0. Корнеев. - М.: Рос. гос. соц. ун-т; Хабаров. краев. спец. 6-ка для слепых, 2017. - 80 с.

9. Раренко М.Б. Аудиодескрипция и тифлокомментирование как особые формы реализации аудиовизуального перевода / М.Б. Раренко // Вестник Московского государственного лингвистического университета. - 2017. - № 10(783). - С. 215-233.

10. Щербакова М. Тифлокомментирование и аудиодескрипция в России и мире. - 15 октября 2018 [Электронный ресурc]. - URL: https://specialviewportal.ru/ articles/post59 (дата обращения: 28.09.2020).

11. Piñero R.B. Audiovisual Translation in a Global Context. Mapping an Ever- changing Landscape / R.B. Piñero, J.D. Cintas. - Palgrave Macmillan, 2015. - 305 p.

12. Yeung J. Media for All: Subtitling for the Deaf, Audio Description and Sign Language / J. Yeung. - Amsterdam: Rodopi, 2007. - 255 p.

(c) Ван Цзоу Ин (woaiyehehua@gmail.com).

Журнал «Современная наука: актуальные проблемы теории и практики»

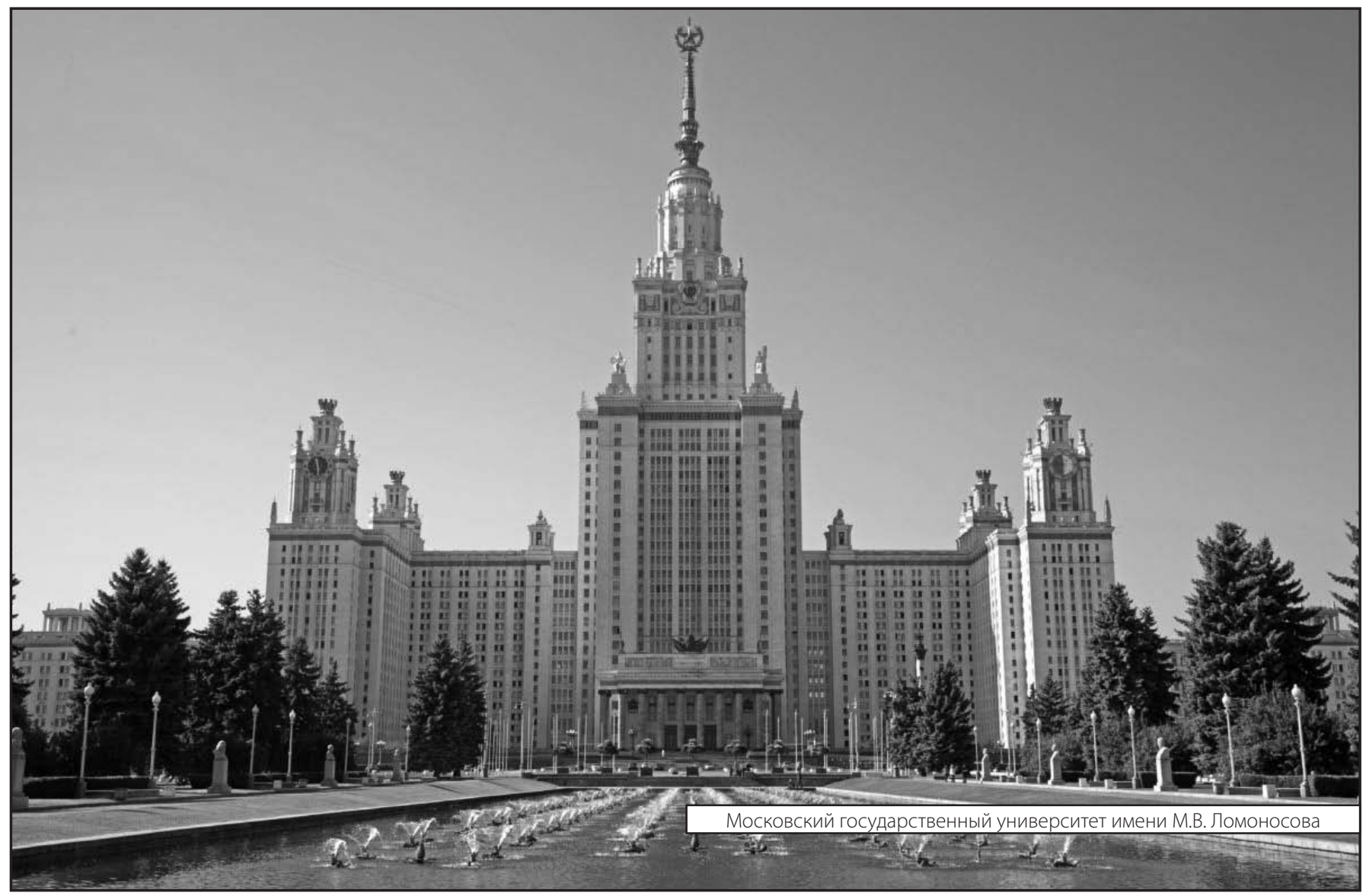

